\title{
Substratos para propagação rápida de mandioca tipo mesa
}

\section{Substrates for rapid propagation of table cassava}

\author{
Aaron de Sousa Alves ${ }^{1}$; Khayran Lopes ${ }^{2}$; Whéllyson Pereira Araújo ${ }^{3}$; Arsenio Pessoa de Melo Júnior ${ }^{4}$ \\ ${ }^{1}$ Doutor em Engenharia Agrícola, Irrigação e Drenagem, Instituto Federal de Educação Ciência e Tecnologia do Piauí, Campus Oeiras, Oeiras, Piauí, \\ +55(99)98415-7100, e-mail: aaron.alves@ifpi.edu.br; 2 Discente do Instituto Federal de Educação Ciência e Tecnologia do Piauí, Campus Oeiras, Oeiras, Piauí, \\ e-mail: lopezinho04@ gmail.com; ${ }^{3}$ Doutor em Engenharia Agrícola, Irrigação e Drenagem, Instituto Federal de Educação Ciência e Tecnologia do Piauí, Campus \\ Paulistana, Paulistana, Piaú, e-mail: wpacordao@hotmail.com; ${ }^{4}$ Doutor em Engenharia Agrícola, Irrigação e Drenagem, Instituto Federal do Sertão \\ Pernambucano, Campus Petrolina zona rural, Petrolina, Pernambuco, e-mail: arseniopessoa@uol.com.br
}

N O T A
C IE N T Í F I C A

Recebido: 19/11/2019

Aprovado: 30/06/2020

Palavras-chave:

Manihot esculenta

Arranjos produtivos

Multiplicação rápida

Key words:

Manihot esculenta

Productive arrangements

Fast multiplication

\section{R E S U M O}

Presente em todas as regiões, a mandioca, tem importância fundamental na alimentação humana e animal, seja como matéria-prima para a obtenção de produtos industriais e/ou na geração de emprego e renda no campo. Em meio à relevância desta cultura para o atual cenário econômico nacional, objetivou-se com este estudo avaliar os efeitos de diferentes composições de substratos sobre o desenvolvimento de estruturas vegetativas de mandioca do tipo mesa mediante a adaptação da técnica de propagação rápida, como alternativa à oferta de mudas de melhor qualidade para comunidades tradicionais inseridas no semiárido piauiense. O experimento foi desenvolvido em ambiente protegido no Instituto Federal do Piauí, Campus Oeiras. Obedecendo ao delineamento em blocos casualizados, sendo testadas 12 composições de substratos formulados a partir da mistura de areia lavada, solo e esterco bovino. A mistura de substratos Solo + Areia lavada + Esterco bovino (1:1:2) e Areia lavada + Esterco bovino (1:2) são eficientes para o desenvolvimento vegetativo das brotações de mandioca do tipo mesa, permitem a obtenção de mudas de melhor qualidade para estabelecimento em campo e, portanto, são recomendados para produção de mudas da cultura no processo de propagação rápida.

\section{A B S T R A C T}

Present in all regions, cassava is of fundamental importance in human and animal nutrition, either as a raw material for obtaining industrial products and for generating employment and income in the field. In the midst of the relevance of this culture to the current national economic scenario, the objective of this study was to evaluate the effects of different substrate compositions on the development of vegetative structures of cassava of the table type by adapting the technique of rapid propagation, as an alternative to offering better quality seedlings to traditional communities in the semi-arid region of Piauí. The experiment was developed in a protected environment at the Federal Institute of Piauí - IFPI, Campus Oeiras. Obeying the randomized block design, 12 substrate compositions formulated from the mixture of washed sand, soil and bovine manure were tested. The Soil + washed sand + bovine manure (1:1:2) and washed sand + bovine manure (1:2) substrates are efficient for the vegetative development of table-type cassava sprouts, allowing better seedling production quality for establishment in the field and are recommended for the production of crop seedlings in the rapid propagation process.

\section{INTRODUÇÃO}

A necessidade de culturas com características de tolerância a condições adversas como presença de pragas e doenças, restrição hídrica, nutricional ou mesmo adversidades climáticas, frequentes em muitas áreas inseridas nos domínios do semiárido brasileiro, requer, constantemente, o aperfeiçoamento de técnicas de cultivo que promovam a utilização racional dos recursos naturais e agrícolas.

\section{Revista Verde}

ISSN 1981-8203

Pombal, Paraíba, Brasil
Além de fatores morfológicos e fisiológicos adequados, os ambientais conferem importância singular para o desenvolvimento inicial de mudas, em que, o tipo de substrato utilizado pode conferir plantas com melhor desempenho em campo. A aeração, drenagem, capacidade de retenção de água e disponibilidade de nutrientes pelos substratos, variam, segundo (SILVA et al., 2011) de acordo com o tipo de material utilizado para a sua formulação. E podem influenciar 
diretamente a formação do sistema radicular e o desenvolvimento da parte aérea das mudas.

Atributos que promovam rusticidade natural, elevada adaptação a condições variadas de clima e solo, rendimento satisfatório sob condições de baixa fertilidade e tolerância a diversos patógenos, proporcionam à mandioca de mesa Manihot utilissima, Pohl (Manihot esculenta, Crantz) grande destaque entre as culturas de interesse econômico, com respaldo em uma ampla distribuição geográfica. Devido a estas particularidades, a mandioca é comumente cultivada por pequenos agricultores, em áreas em que os solos são, em geral, nutricionalmente pobres e sob condições climáticas desfavoráveis à exploração de culturas mais exigentes em nutrientes.

Embora o estado do Piauí figure como um produtor em potencial de mandiocas as produtividades registradas em 2018 não ultrapassaram as 7,4 t ha-1 (IBGE, 2018). Logo, inferior à média nordestina que é de aproximadamente $9,8 \mathrm{t} \mathrm{ha}^{-1} \mathrm{e}$ à média nacional que corresponde a cerca de $14 \mathrm{t} \mathrm{ha}^{-1}$ (GROXKO, 2017).

Esta baixa produtividade observada no estado Piauí, pode ser, atribuída à insuficiente disponibilidade de material vegetal de boa qualidade para o plantio, tendo em vista que no estado, o cultivo de mandioca é caracterizado pela aplicação de métodos tradicionais, associado ao baixo nível tecnológico predominante, em pequenas propriedades de base familiar, o que põe em risco a manutenção da atividade nestas localidades.

Na região noroeste de Minas Gerais, Vieira et al. (2015) observaram que o cultivo da mandioca de mesa ocorre com baixo emprego de tecnologias, as variedades utilizadas, normalmente, não passam por um processo formal de melhoramento genético, sendo suscetíveis à bacteriose e com baixo potencial de produção de raízes tuberosas.

Acredita-se que elementos associados ao envelhecimento fisiológico da própria planta decorridos de multiplicações vegetativas sucessivas, a ocorrência frequente de pragas e doenças, em menor e/ou maior intensidade, podem restringir significativamente a disponibilidade de material vegetal tanto em qualidade quanto quantidade para o plantio, devido a obtenção tradicional das estacas (manivas-sementes).

Uma alternativa ao método tradicional de obtenção manivas-sementes e propagação de mandiocas que pode efetivamente reduzir as falhas no estabelecimento da cultura em campo foi proposto por Ceballos et al. (1980), no Centro Internacional de Agricultura Tropical (CIAT), na Colômbia, que criou uma técnica de propagação rápida de mandiocas que permite obter plantas vigorosas o suficiente que possibilita ampliar em até 100 vezes a taxa de multiplicação de manivassementes.

A técnica de propagação rápida da mandioca, permite reduzir o tempo de estabelecimento da planta quando comparado a propagação sexuada e tem como maior benefício a manutenção das características morfológicas e agronômicas originais (FUKUDA; CARVALHO, 2006).

A concepção das condições ótimas à brotação e enraizamento dessas estruturas, associada à melhor época de plantio, exige conhecimentos técnicos nem sempre disponíveis, em que, a produção de mudas de boa qualidade é uma das dificuldades que se enfrenta nesse processo, exigindo dos pesquisadores estratégias de multiplicação que permita o desenvolvimento de sistemas produtivos mais eficazes e oportunos. Especialmente, para culturas com importância singular no contexto cultural, econômico e social, como a mandioca de mesa. Essa importância aumenta quando a cultura tem comprovado valor nutritivo, compondo um importante suporte para a sustentabilidade alimentar, pois, muitas famílias em situações de vulnerabilidade têm nessa cultura uma significativa fonte de alimento e renda.

Objetivou-se com este estudo avaliar os efeitos de diferentes composições de substratos sobre o desenvolvimento de estruturas vegetativas de mandioca do tipo mesa, mediante a adaptação de técnica de propagação rápida.

\section{MATERIAL E MÉTODOS}

Os estudos foram conduzidos no viveiro de mudas no Instituto Federal do Piauí (IFPI), Campus Oeiras. O local encontra-se à mesorregião Sudeste do estado do Piauí, mais precisamente na microrregião de Picos, sob às coordenadas $07^{\circ}$ 01' 31" de Latitude Sul e $42^{\circ} 07^{\prime} 52^{\prime \prime}$ de Longitude Oeste de Greenwich, a aproximadamente $180 \mathrm{~m}$ de altitude e, cerca de $289 \mathrm{~km}$ da capital Teresina e a $86 \mathrm{~km}$ da cidade de Picos.

Conforme classificação de Köppen a região possui clima do tipo Aw (semiúmido e quente), cuja, precipitação média anual abrange os $1.100 \mathrm{~mm}$ e a temperatura média compreende os $29^{\circ} \mathrm{C}$.

O delineamento experimental utilizado foi o de blocos casualizados, em que foram testados 12 substratos obtidos a partir da mistura de solo, areia lavada e esterco bovino (Tabela 1), com quatro repetições contendo 9 miniestacas cada uma, totalizando 36 miniestacas por substrato.

Tabela 1. Composição dos substratos utilizados para avaliação do desenvolvimento de estruturas vegetativas proveniente de miniestacas de mandioca de mesa, por meio da aplicação da técnica de multiplicação rápida.

\begin{tabular}{|c|c|c|}
\hline SUBSTRATOS & COMPOSIÇÃO & PROPORÇÕES \\
\hline I & Solo & $100 \%$ \\
\hline II & Areia lavada & $100 \%$ \\
\hline III & Solo + esterco bovino & $1: 1$ \\
\hline IV & $\begin{array}{l}\text { Areia lavada }+ \\
\text { esterco bovino }\end{array}$ & $1: 1$ \\
\hline V & Solo + esterco bovino & $2: 1$ \\
\hline VI & $\begin{array}{l}\text { Areia lavada }+ \\
\text { esterco bovino }\end{array}$ & $2: 1$ \\
\hline VII & Solo + esterco bovino & $1: 2$ \\
\hline VIII & $\begin{array}{l}\text { Areia lavada }+ \\
\text { esterco bovino }\end{array}$ & $1: 2$ \\
\hline IX & $\begin{array}{l}\text { Solo }+ \text { areia lavada }+ \\
\text { esterco bovino }\end{array}$ & $1: 1: 1$ \\
\hline $\mathrm{X}$ & $\begin{array}{l}\text { Solo }+ \text { areia lavada }+ \\
\text { esterco bovino }\end{array}$ & $2: 1: 1$ \\
\hline XI & $\begin{array}{c}\text { Solo }+ \text { areia lavada }+ \\
\text { esterco bovino }\end{array}$ & $1: 2: 1$ \\
\hline XII & $\begin{array}{c}\text { Solo + areia lavada }+ \\
\text { esterco bovino }\end{array}$ & $1: 1: 2$ \\
\hline
\end{tabular}

O solo utilizado na composição dos substratos foi proveniente de área agricultável, cultivada com culturas anuais e perenes no campo agrícola do IFPI, Campus Oeiras. Este, por sua vez, foi coletado à camada de $20 \mathrm{~cm}$, transportado ao viveiro de mudas da referida Instituição, onde foi seco ao ar. Após a secagem, retirou-se uma amostra de aproximadamente 500 g e encaminhada ao Laboratório TERRA Análises para Agropecuária Ltda, Goiânia - GO para caracterização química e granulométrica, Tabela 2. 
Tabela 2. Caracterização química e granulométrica do solo utilizado na composição dos substratos.

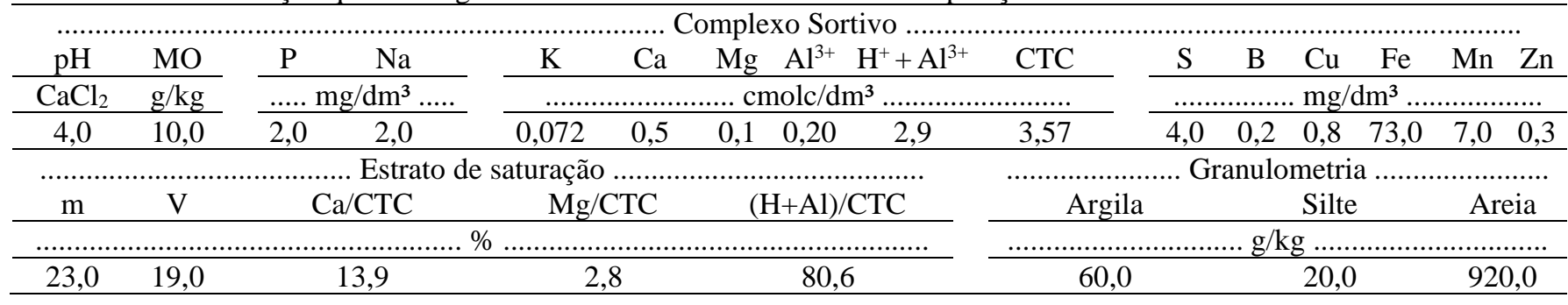

O esterco bovino utilizado no experimento foi adquirido de produtores rurais locados no próprio município de Oeiras PI.

Para se preservar a constância genética da cultura no âmbito do semiárido, realizou-se a coleta de manivas em plantas adultas, previamente selecionadas, de mandioca do tipo mesa, cultivar Peixe, com 10 a 12 meses de idade, cultivadas pelo método convencional no campo agrícola do próprio IFPI - Campus Oeiras.

As manivas coletadas foram anteriormente limpas mediante lavagem em água corrente. Em seguida, foi realizada a eliminação das porções basal e apical destas, a partir da subtração de aproximadamente $30 \mathrm{~cm}$ de ambas as extremidades, preservando-se o terço intermediário, que foi, igualmente, subdividido, com auxílio de serra circular em segmentos de hastes (miniestacas) com $5 \mathrm{~cm}$ de comprimento contendo três a quatro gemas cada um. Feito isto, as miniestacas foram lavadas em água corrente e submetidas a tratamento sanitário em solução de hipoclorito de sódio a $5 \%$ por 1 minuto. Decorrido esse tempo, as miniestacas foram dispostas à sombra, sobre bancadas cobertas com papel toalha para retirar o excesso de umidade.

A multiplicação da cultura ocorreu em meio artificial, com o arranjo das miniestacas em câmaras de propagação, preservando-se a umidade dos substratos e temperatura no seu interior, conforme recomenda Ceballos et al. (1980).

Para este estudo, as câmaras de propagação foram instaladas em ambiente protegido, do tipo telado, construído nas dimensões 9,0 $\mathrm{m}$ de largura, 9,0 $\mathrm{m}$ de comprimento e 2,10 $\mathrm{m}$ de altura em estruturas de sustentação em concreto armado, fios de aço galvanizado $12 \mathrm{~mm}$ tencionados por esticadores do tipo catraca. Coberto e fechado lateralmente com tela de sombreamento do tipo sombrite cor preta que permite a passagem de $50 \%$ da luz solar.

As câmaras de propagação, com capacidade de $40 \mathrm{~L}$ de substrato cada, foram confeccionadas, em formato quadrado, utilizando-se blocos de preenchimento composto, com configuração geométrica vazada pré-fabricados com material cerâmico, nas dimensões de $0,075 \mathrm{~m}$ x 0,19 m x 0,34 m, espessura, largura e comprimento, respectivamente, dispostos lateralmente em pares uns sobre os outros (Figura 1A).

No seu interior foi instalado um sistema de drenagem composto por uma camada de aproximadamente $0,05 \mathrm{~m}$ de espessura de brita $n^{\circ} 1$ arranjadas na base das respectivas câmaras, tela de nylon posta sobre a camada de brita e uma camada de cerca de $0,05 \mathrm{~m}$ de espessura de areia lavada depositada após a tela de nylon. O restante das câmaras de propagação foi preenchido com, aproximadamente $35 \mathrm{~L}$ de substrato formulados para realização deste estudo.

Uma vez realizado o plantio das miniestacas (Figura 1B), os substratos foram irrigados manualmente, utilizando-se água de abastecimento proveniente de poço tubular instalado na área agrícola do IFPI - Campus Oeiras. A umidade dos substratos foi mantida à capacidade de campo, cujas, irrigações foram manejadas quinzenalmente aplicando-se cerca de três litros de água no período.

Figura 1. Montagem das câmaras de propagação e, instalação e condução do experimento com multiplicação rápida de mandioca do tipo mesa cv. Peixe.

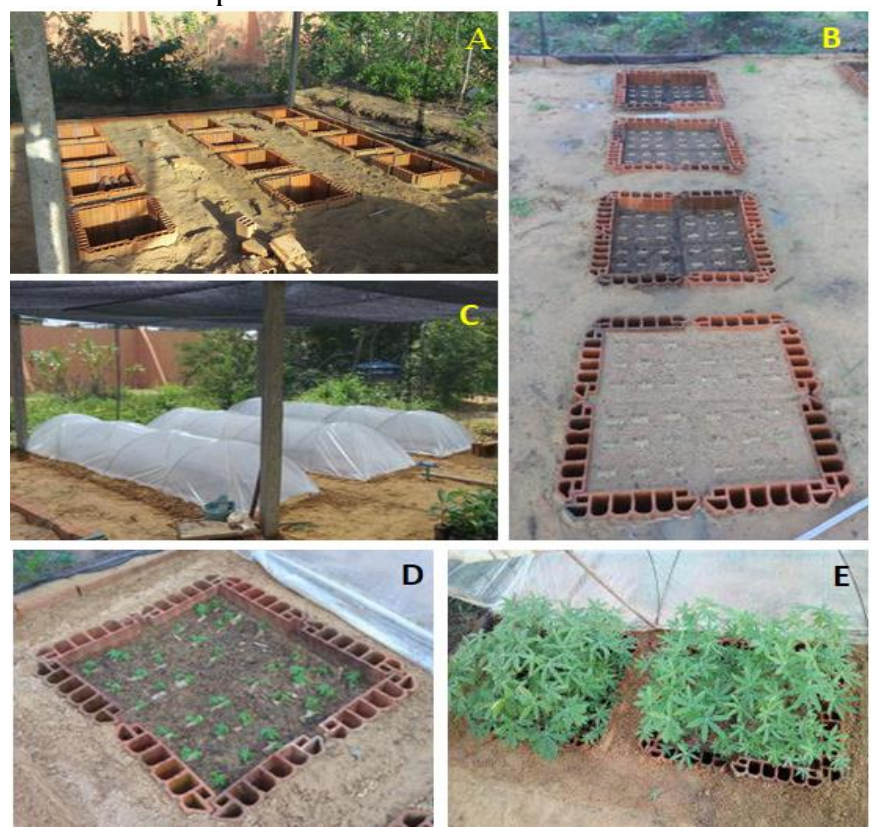

As câmaras de propagação foram cobertas com campânulas plásticas (Figura 1C), com 0,60 m de altura e revestida com filme agrícola para manutenção da umidade e temperatura no seu interior. Foram construídas, em formato retangular, em estrutura montada em tubos de PVC rígido com $25 \mathrm{~mm}$ de diâmetro para formação da base, barras redondas de aço, com superfície nervurada, medindo 4,2 $\mathrm{mm}$ de diâmetro e 1,5 m de comprimento, sendo estas dispostas em posição arqueada e cruzadas transversalmente umas sobre as outras com as extremidades das barras posicionadas sobre as tubulações que compõe a base das campânulas.

Por ocasião a emissão das brotações (Figura 1D) realizouse contagens diárias do total emitido para se determinar de acordo com cada substrato testado, o número de brotações por miniestaca (NBME), a porcentagem de brotações emitidas por miniestacas (\%BME), o índice de brotações (IB) e o índice de velocidade de brotação (IVB), a partir de adaptação de fórmula proposta por Maguire (1962) (Equação 1).

$$
\mathrm{IVB}=\sum_{i=1}^{n}\left(\frac{N i}{D i}\right)
$$

Em que: IVB = índice de velocidade de brotação; N1, N2 ... Ni = número de brotações emitidas nas primeiras, segunda e ... i- 
ésima contagem, respectivamente; D1, D2 ... Di = número de dias na primeira, segunda e ... i-ésima contagem.

Transcorrido tempo suficiente para se realizar a transferência das brotações à câmara de enraizamento, ou seja, quando os brotos atingiram cerca de $10 \mathrm{~cm}$ de altura (Figura 1E) realizou-se as primeiras mensurações de comprimento, diâmetro, número de folhas e, por conseguinte, a porcentagem de brotações emitidas por cada segmento de haste (miniestacas).

As medidas de altura das brotações foram efetuadas com régua graduada em centímetros, tomando-se a distância entre a base e o ápice das referidas estruturas vegetativas. As medidas de diâmetro foram tomadas a uma altura de $1,0 \mathrm{~cm}$ do ponto de inserção entre as brotações e as respectivas miniestacas, com o auxílio de paquímetro digital e por ocasião das avaliações de altura das brotações. O número de folhas foi determinado pelo cômputo das folhas que se apresentaram fotossinteticamente ativas, e por ocasião das avaliações de altura e diâmetro das brotações.

Por ocasião das avaliações do diâmetro, as brotações foram cuidadosamente separadas por corte a $1,0 \mathrm{~cm}$ do solo e, posteriormente, acomodadas em recipientes plásticos com volume de $100 \mathrm{ml}$, devidamente identificados conforme cada tratamento e preenchidos com água potável até $90 \%$ do seu volume total, substituindo-a a cada dois dias. Os recipientes contendo as brotações foram arranjados no interior da câmara de enraizamento construída a $1,20 \mathrm{~m}$ do solo, nas dimensões de $1,5 \mathrm{~m} \times 0,6 \mathrm{~m} \times 1,2 \mathrm{~m}$ (comprimento, largura e altura, respectivamente) coberto e fechada lateralmente com tela de sombreamento do tipo Sombrite ${ }^{\circledR}(50 \%$ de densidade), coberta e fechada lateralmente com filme agrícola, após a tela de sombreamento e, revestida na base, por placas de PVC.
Os dados coletados foram submetidos às análises de variância e, por conseguinte, as variáveis qualitativas foram submetidas ao teste de Tukey a $5 \%$ de significância para comparação das médias. Para estas análises, utilizou-se o software estatístico SISVAR (FERREIRA, 2011).

\section{RESULTADOS E DISCUSSÃO}

Os valores do coeficiente de variação $(\mathrm{CV})$ oscilaram entre $6,47 \%$ e $18,63 \%$, o que torna perceptível a variabilidade entre os ensaios, mas, com indicativo de boa precisão experimental. Condição que representa alta e média precisão experimental, conforme Gomes (2000).

O número de brotações por miniestaca (NBME), índice de velocidade de brotações (IVB), porcentagem de brotações por miniestacas (\%BME) e o comprimento médio das brotações emitidas (CMBE) foram significativamente influenciados $(\mathrm{p}<0,01)$ pelos substratos avaliados. Já o índice de brotações (IB), diâmetro das brotações (DB) e número de folhas das brotações (NFB), não foram influenciadas pelos substratos testados $(p>0,05)$.

A partir dos resultados obtidos, percebe-se que o tratamento contendo apenas areia lavada como substrato, externou os melhores resultados para NBME, IVB e \%BME (Tabela 3). Não diferindo estatisticamente dos substratos solo $(100 \%)$, solo + esterco bovino (1:2), solo + esterco bovino $(1: 1)$, areia lavada + esterco bovino $(2: 1)$, areia lavada + esterco bovino $(1: 1)$, areia lavada + esterco bovino $(1: 2)$, solo + areia lavada + esterco bovino (1:1:2), solo + esterco bovino (2:1), solo + areia lavada + esterco bovino (1:2:1). Por outro lado, as miniestacas de mandioca de mesa cultivadas nos substratos contento solo + areia lavada + esterco bovino nas proporções de $1: 1: 1$ e $2: 1: 1$ produziram valores pouco satisfatórios para estas mesmas variáveis.

Tabela 3. Valores médios para número de brotações por miniestaca (NBME), índice de brotações (IB), índice de velocidade de brotações (IVB), porcentagem de brotações por miniestacas (\%BME), comprimento médio das brotações emitidas (CMBE), diâmetro médio das brotações (DMB) e número de folhas das brotações (NFB) de mandioca do tipo mesa cv. Peixe em meio aos diferentes substratos avaliados.

\begin{tabular}{|c|c|c|c|c|c|c|c|}
\hline \multirow{2}{*}{ Substratos } & \multicolumn{7}{|c|}{ Variáveis analisadas } \\
\hline & NBME & IB & IVB & $\% \mathrm{BME}$ & CMBE & DMB & NFB \\
\hline Solo - $100 \%$ & $1,65 \mathrm{ABC}$ & $55,56 \mathrm{~A}$ & $25,50 \mathrm{ABC}$ & $47,11 \mathrm{ABC}$ & $7,48 \mathrm{BCD}$ & $1,80 \mathrm{~A}$ & $3,50 \mathrm{~A}$ \\
\hline Areia lavada - $100 \%$ & $1,75 \mathrm{~A}$ & $55,55 \mathrm{~A}$ & $27,78 \mathrm{~A}$ & $49,74 \mathrm{~A}$ & $6,60 \mathrm{D}$ & $1,82 \mathrm{~A}$ & $2,71 \mathrm{~A}$ \\
\hline Solo + Esterco bovino $-1: 1$ & $1,68 \mathrm{ABC}$ & $55,56 \mathrm{~A}$ & $26,36 \mathrm{AB}$ & $48,07 \mathrm{ABC}$ & $6,79 \mathrm{D}$ & $1,80 \mathrm{~A}$ & $2,21 \mathrm{~A}$ \\
\hline Areia lavada + Esterco bovino - 1:1 & $1,66 \mathrm{ABC}$ & $56,35 \mathrm{~A}$ & $25,66 \mathrm{ABC}$ & $47,36 \mathrm{ABC}$ & 7,44 CD & $1,94 \mathrm{~A}$ & $3,33 \mathrm{~A}$ \\
\hline Solo + Esterco bovino - 2:1 & $1,58 \mathrm{ABC}$ & $57,94 \mathrm{~A}$ & $23,90 \mathrm{ABC}$ & $45,18 \mathrm{ABC}$ & 7,68 ABCD & $1,95 \mathrm{~A}$ & $2,67 \mathrm{~A}$ \\
\hline Areia lavada + Esterco bovino $-2: 1$ & $1,68 \mathrm{ABC}$ & $54,76 \mathrm{~A}$ & $26,46 \mathrm{AB}$ & $47,85 \mathrm{ABC}$ & 7,86 ABCD & $1,87 \mathrm{~A}$ & $3,00 \mathrm{~A}$ \\
\hline Solo + Esterco bovino - 1:2 & $1,73 \mathrm{AB}$ & $56,35 \mathrm{~A}$ & $27,29 \mathrm{~A}$ & $49,66 \mathrm{AB}$ & $8,42 \mathrm{ABCD}$ & $1,89 \mathrm{~A}$ & $4,08 \mathrm{~A}$ \\
\hline Areia lavada + Esterco bovino $-1: 2$ & $1,66 \mathrm{ABC}$ & $53,18 \mathrm{~A}$ & $25,93 \mathrm{AB}$ & $47,28 \mathrm{ABC}$ & $9,86 \mathrm{AB}$ & $1,89 \mathrm{~A}$ & $5,66 \mathrm{~A}$ \\
\hline Solo + Areia lavada + Esterco bovino - 1:1:1 & $1,27 \mathrm{C}$ & $46,03 \mathrm{~A}$ & $18,56 \mathrm{C}$ & $36,17 \mathrm{C}$ & $9,37 \mathrm{ABC}$ & $1,83 \mathrm{~A}$ & $5,02 \mathrm{~A}$ \\
\hline Solo + Areia lavada + Esterco bovino $-2: 1: 1$ & $1,30 \mathrm{BC}$ & $45,24 \mathrm{~A}$ & $19,48 \mathrm{BC}$ & $37,02 \mathrm{BC}$ & $7,52 \mathrm{BCD}$ & $1,80 \mathrm{~A}$ & $3,48 \mathrm{~A}$ \\
\hline Solo + Areia lavada + Esterco bovino - 1:2:1 & $1,48 \mathrm{ABC}$ & $47,62 \mathrm{~A}$ & $20,83 \mathrm{ABC}$ & $39,51 \mathrm{ABC}$ & $9,41 \mathrm{ABC}$ & $1,88 \mathrm{~A}$ & $5,53 \mathrm{~A}$ \\
\hline Solo + Areia lavada + Esterco bovino $-1: 1: 2$ & $1,65 \mathrm{ABC}$ & $53,17 \mathrm{~A}$ & $25,94 \mathrm{AB}$ & $47,14 \mathrm{ABC}$ & $9,92 \mathrm{~A}$ & $1,76 \mathrm{~A}$ & $5,44 \mathrm{~A}$ \\
\hline
\end{tabular}

Os melhores resultados para NBME, IVB e \%BME observados nos substratos $100 \%$ areia ou naqueles substratos que contem areia em sua composição podem estar relacionados a características físicas conferidas pelo material como drenagem, que neste caso, confere melhor equilíbrio hídrico ao substrato e à aeração na base das miniestacas, promovendo melhores condições para emissão de brotações seguido de posterior enraizamento.
Dutra e Kersten (1996) mencionam que quantidades equilibradas de água e ar, conferidos por drenagem adequada e maior espaço poroso favorecem o desenvolvimento de estacas. Tofanelli et al., (2003), verificaram em sua pesquisa que o equilíbrio na relação água/ar promovido pela vermiculita e areia foram favoráveis à brotação de estacas de pessegueiro 'Okinawa'. Timm et al. (2015) constataram em seus estudos que a vermiculita média e a vermiculita média + areia 
demonstraram ser substratos adequados para a formação de mudas, por miniestaquia, de porta-enxertos de pessegueiro 'Okinawa', 'Flordaguard' e 'Nemared'. Santos et. al (2015), verificaram que dentre os substratos utilizados para produção de mudas de rosa do deserto, que aquele contendo $50 \%$ areia + $25 \%$ solo $+25 \%$ substrato comercial + adubo em sua composição propiciaram a obtenção de plantas mais desenvolvidas.

Quanto ao desenvolvimento vegetativo das brotações, definido pelo CMBE, conforme resultados significativos obtidos em função das diferentes composições de substratos testados (Tabela 3), observa-se que os substratos solo + areia lavada + esterco bovino (1:1:2) e areia lavada + esterco bovino (1:2) foram mais eficientes, verificando-se brotações mais desenvolvidas $9,92 \mathrm{~cm}$ e $9,86 \mathrm{~cm}$, respectivamente. Ainda assim, estatisticamente semelhantes aos substratos contendo solo + areia lavada + esterco bovino nas proporções de 1:1:1 e $1: 2: 1$, Solo + Esterco bovino nos totais correspondentes a 1:2 e $2: 1$ e areia lavada + esterco bovino (2:1). Os demais substratos mostraram-se menos eficientes, visto que, produziram brotações menos desenvolvidas (Tabela 3).

Em termos percentuais, a diferença entre o substrato que proporcionou maior CMBE (solo + areia lavada + esterco bovino - 1:1:2) e aquele que proporcionou a menor CMBE (areia lavada - 100\%) foi de 68,4\% (Tabela 3).

Acredita-se que a adição de areia lavada tenha proporcionado melhores condições de drenagem e aeração ao substrato, visto que, se observou qualidades como melhor retenção de umidade e subsequente disponibilidade de água, e o esterco bovino, por possuir melhores condições químicas, tenha contribuído para o fornecimento de nutrientes necessários ao desenvolvimento das brotações de mandioca. Evidenciando-se, assim, que esta combinação contribuiu para um melhor enraizamento das miniestacas e, por conseguinte, a emissão de brotações mais vigorosas.

A porosidade, a maior capacidade de retenção de água, aeração além dos nutrientes que fornecem são condições peculiares que favorecem o enraizamento de estacas (LIMA et al., 2009; COSTA et al., 2010), uma vez que, substratos porosos facilitam o crescimento radicular (TAVARES et al., 2012) e permitem uma drenagem equilibrada com boa homogeneidade (WEISS et al., 2018). Sendo assim, possibilitam um desenvolvimento adequado da parte aérea das mudas, o que permite a aplicação dos diferentes manejos aplicados à cultura no campo.

Além das características adequadas apresentadas pelos substratos, é importante salientar que o desenvolvimento de brotações em estacas também sofre variações entre as diferentes concentrações de ácido indolbutírico, podendo o maior crescimento de brotações estar relacionado, também, com o enraizamento (LIMA et al., 2016). Neste sentido, temse que pontos de crescimento radicular em formação constituem locais de síntese de citocininas, que são translocadas aos pontos de crescimento na parte área, estimulando a multiplicação celular (TAIZ; ZEIGER, 2013). O que permite o entendimento da relação entre brotações e o desenvolvimento do sistema radicular em estacas.

\section{CONCLUSÕES}

A mistura de substratos Solo + Areia lavada + Esterco bovino (1:1:2) e Areia lavada + Esterco bovino (1:2) são eficientes para o desenvolvimento vegetativo das brotações de mandioca do tipo mesa, permitem a obtenção de mudas de melhor qualidade para estabelecimento em campo e, portanto, são recomendados para produção de mudas da cultura no processo de propagação rápida.

\section{REFERÊNCIAS}

CEBAlloS, L. F.; TORO, J. C.; SILVA, J. R. Sistema de propagacion rápida de la yuca. Centro Internacional de Agricultura Tropical - CIAT. 1 ed. Cali: CIAT, 1980. 12p.

COSTA, E.; GOMES, V. A.; SILVA, P. N. L.; PEGORARE, A. B.; SALAMENE, L. C. P. Produção de mudas de goiabeira por estaquia em diferentes recipientes e substratos. Revista Agrarian, v.3, n.8, p.104-110, 2010.

DUTRA, L.; KERSTEN, E. Efeito do substrato e da época de coleta dos ramos no enraizamento de estacas de ameixeira (Prunus salicina Lindl.). Ciência Rural, v.26, n.3, p.361-366, 1996. 10.1590/S0103-84781996000300003

FERREIRA, D. F. Sisvar: a computer statistical analysis system. Ciência e Agrotecnologia (UFLA), v.35, n.6, p.10391042, 2011. 10.1590/S1413-70542011000600001

FUKUDA, W. M. G.; CARVALHO, H. W. L. de. Propagação rápida de mandioca no Nordeste brasileiro. Cruz das AlmasBA: Embrapa Mandioca e Fruticultura Tropical, 2006. 6 p. (Circular Técnica, 45).

GOMES F. P. Curso de estatística experimental. $14^{\mathrm{a}}$ ed. Piracicaba, Degaspari. 477p., 2000.

GROXKO, M. Análise da conjuntura agropecuária safra 2017/18: mandioca. Secretaria da agricultura e do abastecimento departamento de economia rural. Paraná. 2017.

IBGE. Instituto Brasileiro de Geografia e Estatística. Sistema IBGE de recuperação automática - SIDRA. Rio de Janeiro: IBGE, 2018.

LIMA, D. M.; KLEIN, A. W.; SALLA, V. P.; MOURA, A. P. C.; DANNER, M. A. Ácido indolbutírico no enraizamento de estacas de Langerstroemia indica em diferentes substratos. Pesquisa florestal brasileira, v.36, n.88, p.549-554, 2016. 10.4336/2016.pfb.36.88.1022

LIMA, D. M.; TANNO, G. N.; PURCINO, M.; BIASI, L. A.; ZUFFELLATO-RIBAS, K. C.; ZANETTE, F. Enraizamento de miniestacas de espinheira-santa (Maytenus ilicifolia Mart. ex Reissek). Ciência Agrotecnologia, v. 33, n. 2, p. 617-623, 2009. 10.1590/S1413-70542009000200040

MAGUIRE, J. D. Speed of germination-aid in selection and evaluation for seedling emergence and vigor. Crop Science, v.1, n.1, p.176-177, 1962. 10.2135/cropsci1962.0011183X000200020033x

SANTOS, M. M.; COSTA, R. B.; CUNHA, P. P.; SELEGUINI, A. Tecnologias para produção de mudas de rosa do deserto (Adenium obesum). Multi-Science Journal, UrutaíGO, v.1, n.3, p.79-82, 2015. 10.33837/msj.v1i3.124 
SILVA, E. A.; OLIVEIRA, A. C.; MENDONÇA, V.; SOARES, F. M. Substratos na produção de mudas de mangabeira em tubetes. Pesquisa Agropecuária Tropical, Goiânia-GO, v.41, n.2, p.279-285, 2011. $\underline{10.5216 / \text { pat.v41i2.9042 }}$

TAIZ, L. E ZEIGER, E. Fisiologia vegetal. 4.ed. Porto Alegre: Artmed, 2013. 820 p.

TAVARES, I. B.; MOMNTÉ, V. G.; BARRETO, H. G.; CASTRO, H. G.; SANTOS, G. R.; NAS-CIMENTO, I. R. Tipos de estacas e diferentes substratos na propagação vegetativa de erva cidreira (QUIMIOTIPOS I, II e III). Bioscience Journal, v.28, n.2, p.206-213, 2012.

TIMM, C. R. F.; SCHUCH, M. W.; TOMAZ, Z. F. P.; MAYER, N. M. A. Enraizamento de miniestacas a partir de ramos herbáceos de porta-enxertos de pessegueiro, em diferentes substratos. Revista Inova Ciência \& Tecnologia, Uberaba, MG, ano1, n.1, p. 18-22, 2015.

TOFANELLI, M. B. D.; RODRIGUES, J. D.; ONO, E. O. Enraizamento de estacas lenhosas de pessegueiro cv. Okinawa em diferentes diâmetros de ramos, substratos e recipientes. Ciência Rural, Santa Maria, v.33, n.3, p.437-442, 2003. 10.1590/S0103-84782003000300007

VIEIRA, E. A.; FIALHO, J. F.; CARVALHO, L. J. C. B.; MALAQUIAS, J. V.; FERNANDES, F. D. Desempenho agronômico de acessos de mandioca de mesa em área de Cerrado no município de Unaí, região noroeste de Minas Gerais. Científica, v.43, n.4, p.371-377, 2015. 10.15361/1984$\underline{5529.2015 \mathrm{v} 43 \mathrm{n} 4 \mathrm{p} 371-377}$

WEISS, E. C.; PILONETTO, D.; ANTUNES, R.; MASIERO, M. A.; LIMA, D. M. Estaquia de Sanchezia oblonga com a utilização de diferentes substratos. Natureza online, v.16, n.3, p.001-007, 2018. 